\title{
National Engineering Education Delivery System (NEEDS)
}

Alice M. Agogino

Jaya Krishnagopalan

\section{INTRODUCTION}

The Synthesis Coalition, supported by the National Science Foundation and industrial partners, is comprised of the following eight educational institutions: California Polytechnic State University at San Luis Obispo, Cornell, Hampton, Iowa State, Southern, Stanford, and Tuskegee Universities, and the University of California at Berkeley [1].

The National Engineering Education Delivery System (NEEDS) is an entirely new courseware development and distribution system which will provide widespread, rapid, electronic access to an almost arbitrarily large number of diverse instructional modules [2-4]. Curricular material in the NEEDS database are organized by a diverse range of indices. Links across disciplines are provided in the form of "curricular paths" through the elements in the database. This year, NEEDS will be available not only to this Coalition but to all engineering schools, both as a library/database and a broad distribution channel for the results of their work in developing new concepts, methods, curricula and tools.

\section{NEEDS ADDRESSES KEY ISSUES IN ENGINEERING EDUCATION TODAY}

Synthesis is developing blueprints for model programs that will systematically restructure our undergraduate curricula to meet the needs and competitive pressures of the twenty-first century. Our strategy [5] for curricular reform and courseware development is directed towards addressing the key issues below:

1. Synthesis Interdisciplinary Content: Engineering curricula must expose students to creative synthesis and open-ended problem solving experiences, teaching process in addition to content. Synthesis curricula will emphasize interand multidisciplinary areas of engineering that are critical to national competitiveness.

\author{
Sheri Sheppard \\ Kate Mink \\ James Harris Lawrence Genalo
}

Dave Martin _ John Saylor

2. Concurrent Engineering and Industry Practice: Concurrent engineering and life-cycle design will be taught. Because concurrent application of multiple disciplines through the design cycle often requires team design experience, team building and group experiences will be included. Industry must be brought into the classroom through involvement in Synthesis projects and multimedia case studies of engineering design.

3. Laboratory/Hands-On Experience: The laboratory courses must offer students hands-on experience in solving open-ended engineering problems requiring teamwork, experimental design, and the integration of phenomenological theory with actual system behavior. The computer should be central in the laboratory experience in controlling experiments and providing data acquisition, system modeling, and data analysis capabilities.

4. Communication and Social Context: Engineering is a social activity. The engineer as a decision maker must be able to evaluate and communicate the social implications of technology. The engineer as a driver of product realization must work with multidisciplinary teams, customers, and vendors. Synthesis curricula must provide opportunities for students to develop their written, verbal, and graphical communication skills. We must design opportunities for students to participate in teamwork with people of different levels of experience and diverse backgrounds. Societal factors and sensitivity to ethnic and cultural diversity will be an important element in synthesis curricula.

5. Advanced Delivery Systems and Learning Environments: NEEDS will drive revolutionary change in the classroom. Courseware modules must be designed for easy update and effective use in a wide range of settings, including classrooms, laboratories, and other student environments. Courseware must be designed to draw out active learning and accommodate different learning styles among the student 
population. It must also emphasize creative use of time with less drudgery and rote lectures. NEEDS will facilitate rapid transfer of new technologies into the curriculum through its modular approach and as a shared resource.

Synthesis is developing courseware material in digital form to create a synergistic relationship between the curricular reform efforts and the supporting infrastructure provided by NEEDS infrastructure (described below).

\section{THE NEEDS SYSTEM}

The cornerstone for Synthesis is NEEDS, the National Engineering Education Delivery System, consisting of three major groups: (1) the NEEDS distributed database, (2) the NEEDS courseware development studios, and the (3) NEEDS delivery system/learning environments. In addition, a Technology Transfer organizational structure is being developed to facilitate the transfer of NEEDS technologies between and among Coalition campuses and other users of Coalition educational products.

\section{NEEDS Database Server and Access System}

The NEEDS distributed database supports the concept of a courseware curriculum matrix (Fig. 1) - an extensively crossed-indexed repository of interactive courseware modules, video segments, simulations, slide images, graphics, hardware links and text material (such as lecture notes, exercises or problem sets) - accessed by NEEDS servers which are connected to the National Research and Education Network (NREN), the information superhighway being proposed as the future goal of the Internet. Through the network, faculty and students in classrooms, courseware studios, laboratories, and their offices and rooms, will be able to access the curricular modules from terminals, microcomputers or workstations. Faculty will be able to find, preview, select, and program material for their classes quickly and easily. Students will be able to find and access tutorial material, as well as classroom and laboratory exercises.

Although the NEEDS database is comprised of a distributed set of archive nodes (Fig. 2), the NAS (National Access System) provides a search engine over a centralized library catalog with pointers to the digital course material on the distributed nodes which serve it (Fig. 3). Front-end interfaces to the NEEDS database such as NINa (NEEDS Image Navigator) extends the existing capabilities of current on-line library catalogs by supporting image searches for curricular modules and data elements stored in portable multimedia formats. The current operating version of NINa uses the ImageQuery [6] software developed at UC Berkeley and can be accessed on internet from any $\mathrm{X}$-Window client (e.g., Unix workstations, Mac X on the Apple Macintosh platform, and Xterm on PCs.) Sample windows for the Driil Dissection courseware module [7] are shown in Fig. 4. We are currently developing client software for Apple Macintosh and Windows interfaces as well.

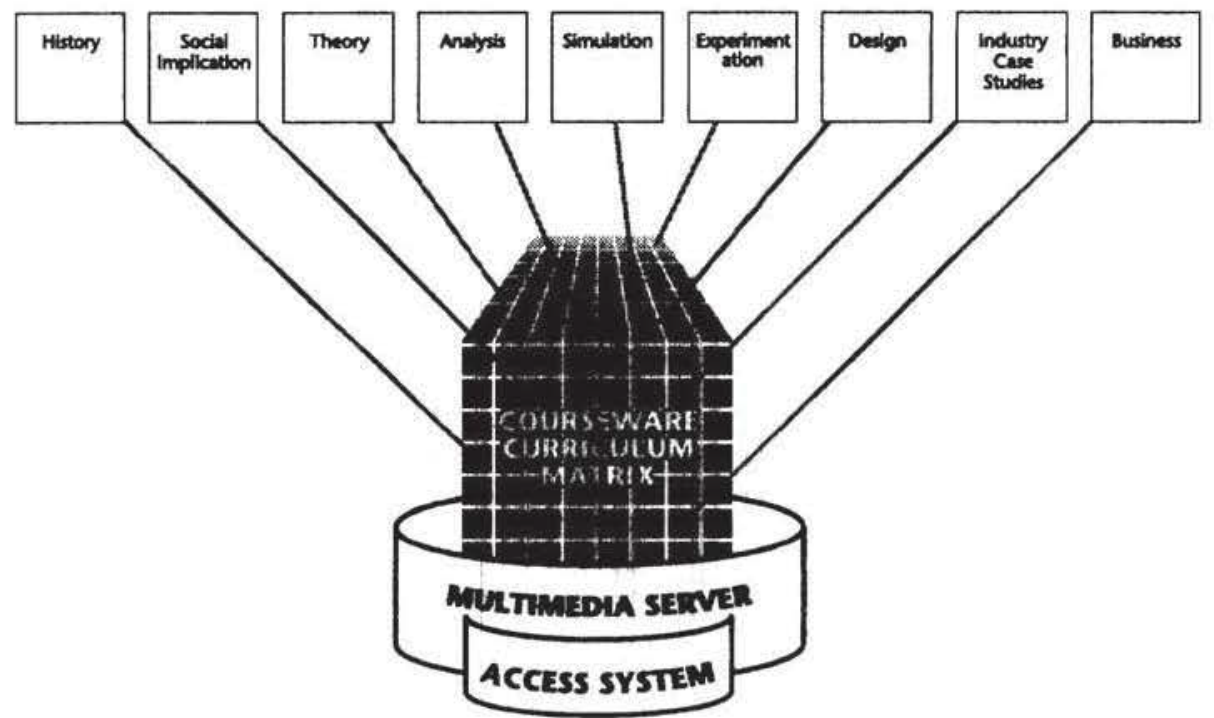

Fig. 1: NEEDS Courseware Curriculum Matrix 


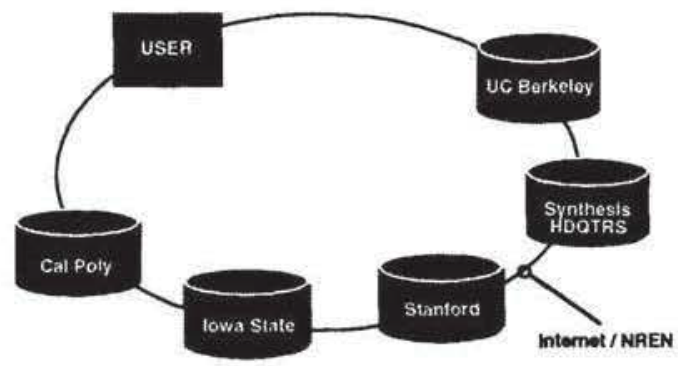

Figure 2: Current NEEDS Database of Distributed Archive Nodes

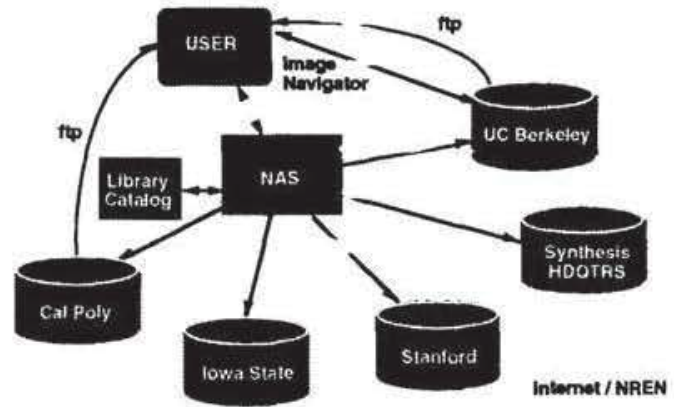

The long term goals of the Synthesis Coalition are to expand access to the NEEDS database through some of the rapidly growing alternate modes of navigating the internet. As an example, we are exploring the possibility of making some of the NEEDS archive nodes work as gopher servers as well, using the WAIS (Wide Area Information Server) indexing scheme and the MARC records associated with each courseware element in NEEDS.

\section{Courseware Development Studios}

The NEEDS courseware development studio $[4,8]$ consists of a facility with hardware and software, network connectivity, a technical library, and support staff, that assists faculty in preparing curricular modules. The studio provides a costeffective approach to the development of engineering courseware by integrating information in its multitude of forms and providing tools to facilitate the authoring process and minimizing the effort and resources required for the courseware development. Courseware development studios may include one central facility at the university level and/or college and departmental installations, as appropriate to each campus. Network connectivity to NEEDS will make possible a high degree of collaboration and resource-sharing between these various sites (Fig. 5).

Figure 3: NAS (National Access System) of NEEDS)

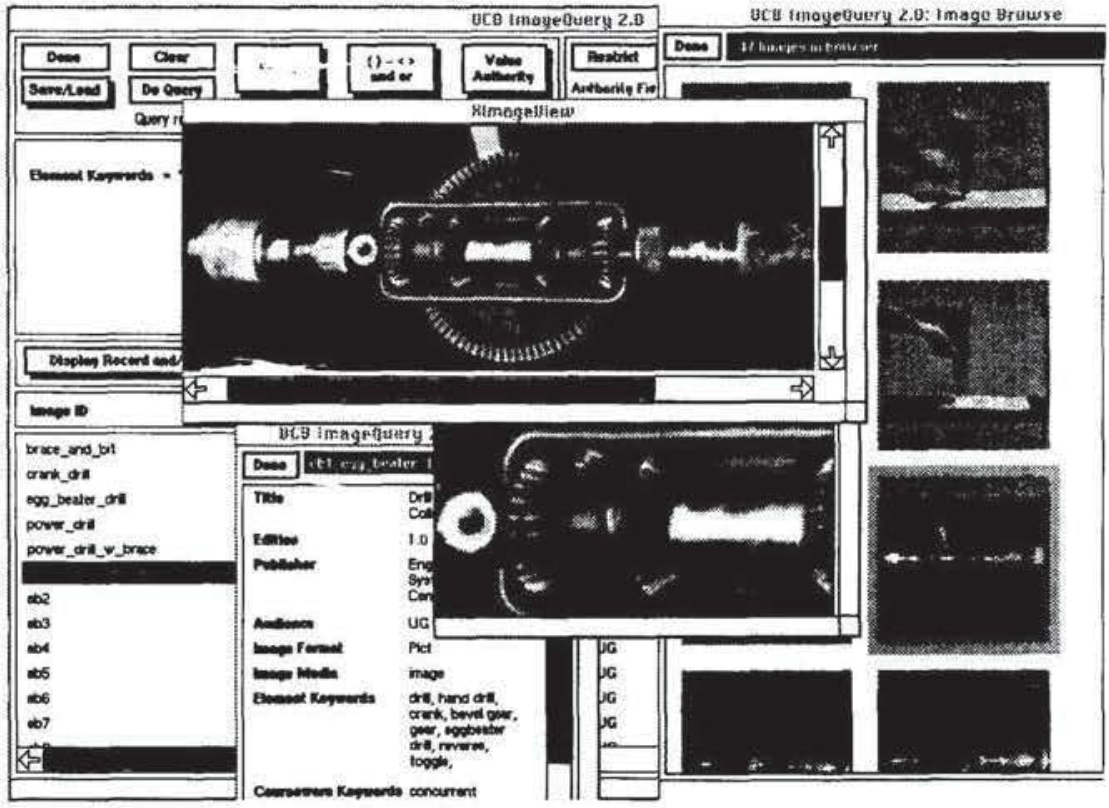

Figure 4: Screen Dump of "Drill Dissection" Image Files from NINa 


\section{SYSTEMS ENGINEERING VIEW}

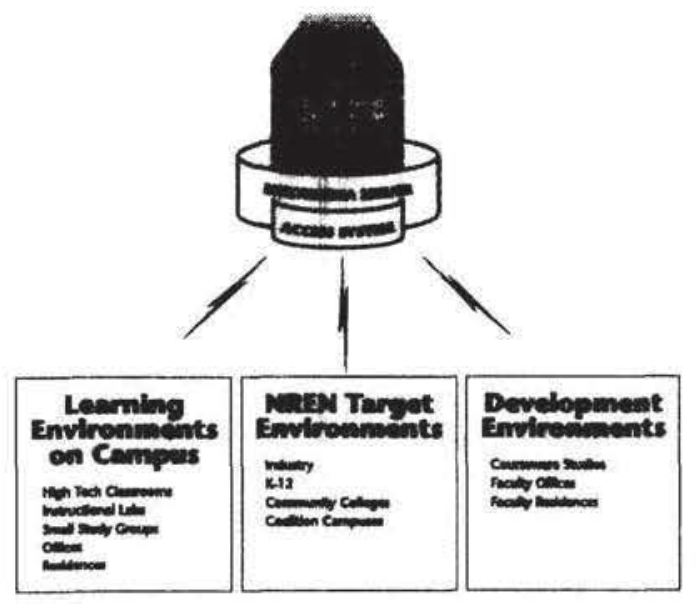

Fig. 5: NEEDS Access and Delivery

\section{High Technology Learning Environments}

NEEDS delivery systems/learning environments consist of a range of high technology environments (including classrooms, computer and experimentation labs, design studios and small study groups) that have access to the NEEDS database, and are capable of presenting the courseware modules in real-time (Fig. 5). It is important that there is faculty and student access to courseware modules through the local and NREN-supported network capability to either the university on-line library or the NEEDS database. (For more detail see papers [9-11].)

\section{Curricular Elements in the NEEDS Database}

At the core of NEEDS is the muti-dimensional courseware matrix or indexing system. The NEEDS database consists of short digitized educational elements that are in a number of forms [5]

1. Educational elements are basic building blocks of courseware such as short video clips, photos, interviews, sound bites, or scanned images.

2. Courseware elements/modules are collections of educational elements that address a single engineering concept.

3. Applications software are large-scale utilities such as spatial reasoning packages or simulation programs.

4. Hardware links are either digital records, such as drawings and components lists that will permit construction of hardware portions of a course, or pointers to the location of actual hardware available for distribution.

5. Complete courseware is an assembly in digital form of all material needed to instruct a complete course.
The NEEDS Infrastructure is a system. Therefore, in the spirit of using good engineering principles, Synthesis has an explicit system engineering basis. Fig. 6 shows a typical educational transfer system with faculty driving the development of the curriculum and delivering its contents through lectures or laboratory classes. Student assessment is used to improve both the content of the curriculum and its delivery.

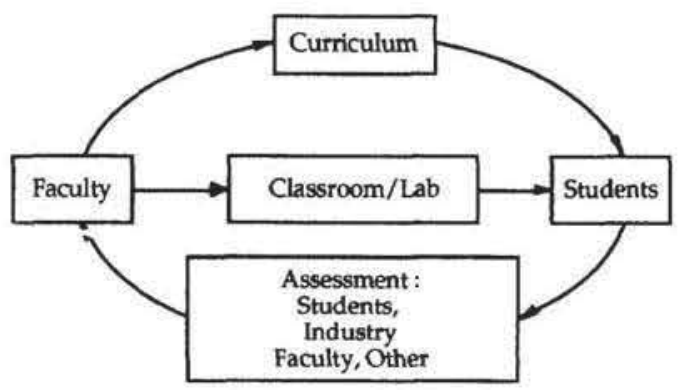

Figure 6: Typical Educational Transfer System

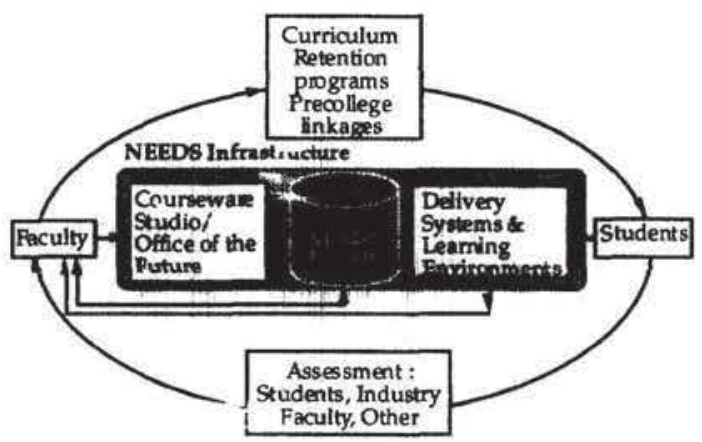

Figure 7: System Engineering Model for Synthesis Infrastructure

The diagram in Fig. 7 expands this model to show the role of NEEDS in developing and delivering courseware-intensive undergraduate curricula as well as downward extc.-ible versions for use in precollege outreach programs. Courseware and its elements can be both retrieved from and stored in the NEEDS database from the studio or from the faculty "office of the future", whereas we expect display only to be the primary use of the NEEDS database in the various delivery systems and learning environments There are faculty and NEEDS interfaces with the curriculum and related pipeline projects at each university.

The key element in the use of the NEEDS Infrastructure is the faculty, who drive the curricular development. Students are the primary 
recipients, but students as well as industry, faculty peers and society at large provide the stakeholder basis for assessing the educational system and providing feedback for improvement.

The Library implicitly plays a key role in all of the NEEDS Infrastructure. It interfaces with all components, either directly, or indirectly through the faculty and students. It provides the intellectual description of the material (cataloging), the storage of the archivally important material, and the training for the access of the materials and for how they fit into the rest of the information universe.

The fundamental assessment of the value of the NEEDS Infrastructure will be determined by assessing the improvement in the education of engineering undergraduate students, and by measuring the associated change in the diversity of the undergraduate engineering student body. NEEDS technologies and courseware developed out of it must undergo a continuous process of improvement through formal assessment methods.

\section{SUMMARY}

The Synthesis Coalition strives to become a model for the rest of the engineering education community through its development of the NEEDS Infrastructure and its pioneering use of this infrastructure to create new methods for teaching and learning undergraduate engineering principles. The long range goal is to develop the NEEDS Infrastructure into a national resource for the undergraduate engineering education community in the 21st century. Preliminary planning for this expansion has been initiated by the National Science Foundation and the Synthesis Coalition.

The Synthesis courseware studio model outlined here offers two important advantages: genuine support of collaboration and economies of scale. We believe Synthesis can take a unique leadership position, not only in courseware development per se, but also in collaborative courseware development. Instead of supporting eight disjoint and different efforts at eight schools, we are creating a single megastudio, with branches at each campus. A model for this can be found in modern libraries, where electronic cataloging and interlibrary loans have effectively transcended the limitations of a physically distributed system.

Courseware studios, delivery systems and learning environments are the important "front doors" that allow students and instructors to enter the NEEDS database to obtain elements that can be used to create and present engineering lesson modules. The ability to create a coherent working model that provides a vehicle for producing, storing, and retrieving multimedia lessons across a nationwide network for concerned educators and students from divergent backgrounds and geographies will determine the success of the NEEDS concept.

\section{ACKNOWLEDGEMENTS}

As the realization of NEEDS presented here is based on a highly collaborative effort, the authors wish to acknowledge the contributions of all team members and project leaders of the Synthesis Infrastructure Team. For up to date information on how to gain more information on NEEDS or access to it send email to jms1@cornell.edu or call Synthesis Headquarters at (607) 255-3697. For information on direct access to NINa send email to bwood@euler.berkeley.edu.

\section{REFERENCES}

[1] Ingraffea, A.R., T. Henderson, A.M. Agogino, A. Eide, and J. Aceto, "Synthesis: A National Engineering Education Coalition," New Approaches to Undergraduate Engineering Education III, Engineering Foundation Conference, Banff, Canada, July 28-Aug. 2, 1991.

[2] Eide, A.R. (Iowa State), R.J. Thomas (Cornell), "The Impact of Technology on Undergraduate Education", Proceedings of the 1992 Frontiers in Education Conference, Nashville, TN, Nov. 11-14, 1992, pp. 625-627.

[3] Synthesis Coalition, Standards Study Report 1.0, March 1993.

[4] Synthesis Coalition, NEEDS Implementation Plan, 2.0, June 1993.

[5] Synthesis Coalition, Strategic Plan, Version 5.0, April 1, 1993.

[6] Watkins, B.T., "Information Technology: Computerized Catalogs Extend Access to Specialized Collections," The Chronicle of Higher Education, June 10, 1992, Vol. 38, No. 40.

[7] Sheppard, Sheri (Stanford), "How Things Work-Freshman Course,"Proceedings of the 1992 Frontiers in Education Conference,, Nashville, TN, November 11-14, 1992.

[8] Huston, Jeffrey C., Christoph Hiemcke, and Peter Barrance (Iowa State), "Incorporating Multimedia Courseware into the Instruction of Undergraduate Dynamics," Proceedings of the 1992 Frontiers in Education Conference," TN, November 11-14, 1992.

[9] Genalo, Lawrence J. (Iowa State), "New Technologies in Engineering Classrooms," Proceedings of the 1992 Frontiers in Education Conference, Nashville, TN, November 11-14, 1992.

[10] Genalo, L. J., "Cost Effective High Technology Classroom Delivery Systems, Proceedings of the 1993 ASEE Conference, Pp. 620-623, Champagne-Urbana, IL, June 1993.

[11] Genalo, L.J., "NEEDS: High Technology Delivery Systems, Proceedings of the 1993 Frontiers in Education Conference, Washington, D.C., Nov. 6-9, 1993.

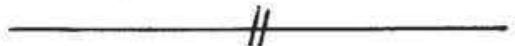

